\title{
Mass Customisation in Sustainable Networked Enterprises
}

\author{
Antonio Giovannini ${ }^{1,2,3}$, Alexis Aubry ${ }^{1,2}$, Hervé Panetto ${ }^{1,2}$, and Hind El Haouzi ${ }^{1,2}$ \\ ${ }^{1}$ CNRS, CRAN UMR 7039, France \\ ${ }^{2}$ Université de Lorraine, CRAN UMR 7039, Boulevard des Aiguillettes \\ B.P. 70239 F-54506 Vandœuvre-lès-Nancy, France \\ ${ }^{3}$ TRANE SAS, rue des Amériques, 88190 Golbey, France \\ \{antonio.giovannini, alexis.aubry, \\ herve.panetto, hind.el-haouzi\}@univ-lorraine.fr
}

\begin{abstract}
To cope with the customer-oriented business model in a global competitive market, enterprises tend to be networked for achieving mass customisation: i.e. offering customisable products with the same efficiency as mass production. This scenario highlights two faces of variability: variability of needs (on customer side) and variability of organisations (on production side). Both types of variability induce a huge number of specified products, namely configurations. This configuration variability must be efficiently managed. This position paper discusses trends and issues for rationalising the number of configurations: i.e. engineering the right number of configurations that match both the customer needs and the production strategy. After this positioning, we propose a systemic perspective for addressing the discussed issues from a sustainability point of view. Finally we give a perspective for a product line definition method that leads to models that meet the discussed variability rationalisation.
\end{abstract}

Keywords: mass customisation, collaborative network, product lines, sustainability.

\section{Introduction}

Nowadays enterprises tend to a customer oriented business model, but at the same time, the stress is on the efficiency of the organisation. The mass customisation concept fits perfectly these trends, but the consequent product variability and the high production volumes often lead enterprise to network. Then, this complex scenario reveals another source of variability, coming from the heterogeneity of manufacturing facilities in the network.

In this position paper, we analyse the nature of these kinds of variability in order to propose a method for a product line definition in this scenario. The aim of the resulting product line is to rationalise those sources of variability rather than reduce them: reducing the first one, we quit a portion of market; reducing the second one, we abandon advantages coming from the enterprise networking. Therefore, the paper will 
also show the impacts of the rationalization strategy on the sustainability character of the network.

The structure of the paper is the following: in the section 2, we analyse the mass customisation concept (seen as first source of variability), showing the transition toward the enterprise networking (seen as second source of variability); in section 3 , a state of the art of product lines is described according the impact on the variability management for mass customisation and enterprise networking; in section 4, following a systemic vision, the gaps between current approaches and a possible solution are highlighted and our perspective to fill this gap; moreover at the end of section 4, the implications of this approach on sustainability are discussed; section 5 is dedicated to conclusions and future work discussion.

\section{From Mass Customisation to Networking}

\subsection{Customisation: A $1^{\text {st }}$ Source of Variability}

If we were a shirt manufacturer: what if technology made it possible for every one of the five thousand shirts to be customized while on the assembly line [...] produced just as quickly as the five thousand identical shirts, yet at not greater expense? Starting from these words, Davis introduced for the first time in [1] the term Mass Customisation (MC). The MC concept is also analysed in [2] and [3]. In these works, the authors identified two other perspectives of the MC concept: 1) during the selling process, the aim is to offer to the customer, the same product customisation capabilities as an engineer-to-order organisation; 2) during the manufacturing process, the aim is to manage the production variability with the same organisational efficiency as in mass production.

The one-funnel schema in the Fig. 1 describes these two effects. The enterprise has to manage the variability due to different customer's needs. Therefore at each order entry, a transformation has to be performed (on the left side of the figure) from the list of customer's needs to the features of the customized product. A further transformation (on the right side of the figure) is needed in order to find the appropriate organisation of processes and resources (i.e. efficiency optimisation) at the manufacturing level.

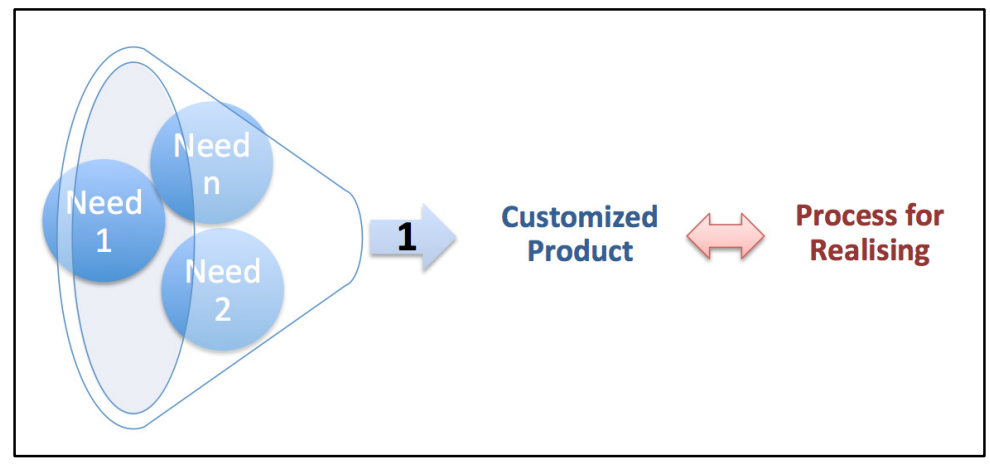

Fig. 1. Variability for MC (i.e. customer's needs) 


\subsection{The Need of Networking: A $2^{\text {nd }}$ Source of Variability}

In MC scenarios, the dynamic network of enterprise operating units (i.e. specific processes or tasks) that allows to decrease the complexity in managing product variability is a quasi-mandatory strategy [3] and is even a requirement [15]. Moreover, by definition, the term MC induces not only variability, but also the presence of high production volumes. Therefore, in the current turbulent market, companies tend to build collaborative networks in order to cope with these two challenges. The enterprise networking implies sharing risks, resources, responsibilities, and rewards [4]. In this particular scenario, if the reduction of the single enterprise efforts is easily understandable, the impacts on variability are not evident.

Comparing the Fig. 1 to the Fig. 2, there are in Fig. 2 different realization possibilities corresponding to different manufacturing facilities involved in the network. That means that another source of variability has to be taken into account.

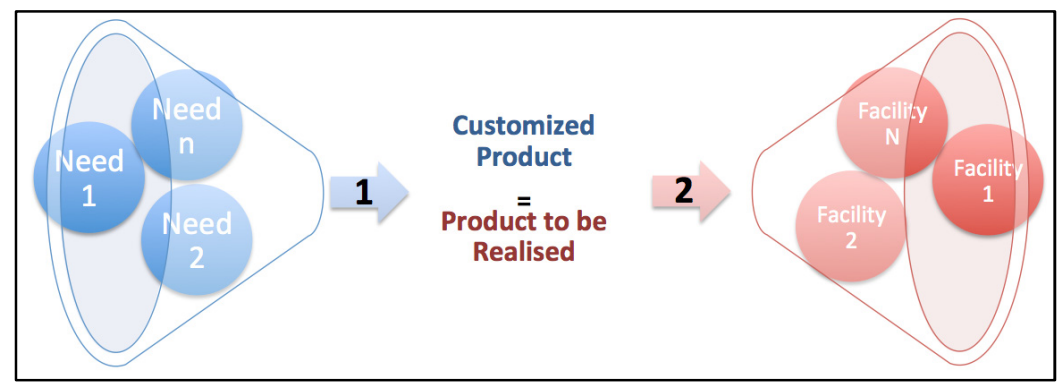

Fig. 2. Variability for MC (i.e. customer's needs) in enterprise network (i.e. manufacturing facilities)

\section{$3 \quad$ Product Lines for Managing Variability}

A commonly accepted solution [5-9] for coping with the previously highlighted two kind of variability is to place, during the order entry process, between the customer and the product to be manufactured, a product configuration software tool. It is based on a product model in which customer can enter values for some options in order to define a specific product. This kind of tools is able to create manufacturable products based on configuration rules formalised by designers. At the design stage, the manufacturability of all possible customised products is verified. Usually this kind of product model is named in different ways, e.g. product family [10], configurable product model [11] or product line [12, 13]. The name Product Lines (PLs) will represent here all these types of models.

\subsection{Product Lines for Mass Customisation}

In this section, we show how the current solution in the domain of PLs can fit the MC variability (on the left side of the Fig. 1 and Fig. 2). In this case, PLs have to be able 
to identify a link between needs expressed by customers and the corresponding customised product that can be manufactured by the enterprise.

In [14], authors define an ontology for engineering design in which they define the concept of requirement. According to them, requirements are properties of artefacts to be designed. Customer needs are considered to be fuzzy and incomplete; therefore a refinement is required to make them usable.

In [15], the authors present a product configuration tool developed in JAVA and based on CBR (Case Based Reasoning) and constraints representation of PL. The case studied is related to a personal computer $(\mathrm{pc}$ ) configurator: here most of customer needs are components such as RAM, CPU, etc. These variables evidently describe pc components but not customer needs and not even how the pc meets those needs. In [16], the authors present an initial PL metamodel formalized in UML. Here, customer requirements are defined as a set of values for product attributes.

In [17], the authors justify the importance of a constraint based representation of PL: the product configuration (PC) process is performed solving a constraint satisfaction problem (CSP). They propose a four-concept model: customer requirements (i.e. the needs), component types, design parameters and design constraints. As in other works, the authors mean for needs, the product functions.

In [18], the authors formulate the PC as a multi objective configuration problem. They apply a genetic algorithm to solve the problem. Also in this case, the product functions are used for interfacing the customer with the PL.

In [11], the authors try to extend the configuration impact on customer satisfaction and on production planning. Here customer requirements are products or product components properties.

In [19], the authors propose a method (for an assembly-to-order product) for taking into account the customer and the manufacturer utility at the same time in a PC. A genetic algorithm is used for solving the CSP. Here, the customer requirements are represented as product properties.

In [20], the authors use a technique based on the application of fuzzy multiple attributes decision making for PC. Customer requirements are represented as product technical specifications and prices.

In [10], the authors represent the PC as an optimization problem of customer satisfaction. A genetic algorithm is deployed for finding a solution. Graphs are used for linking product components features with customer needs, but here customer needs are still product features.

In [21], the authors propose a modular-based PC process. The most remarkable point of this paper is the classification of customer needs: binary, optional, parameter, description and explanation types. We can yet state that needs are seen as product specifications.

In [22], the authors represent the PC process in a two-stages translation: from customer requirements to product functions; from product functions to product modules. Also here, requirements are expressed by means of product components or product features.

In $[12,23]$, the authors represent the PL in a CSP. In the first paper a definition of configuration needs is given: anyway the configuration needs are represented on the basis of product component features. 
The analysis of the state of the art shows that current PLs engineering methods are not completely formalising the link between the customer needs and the customised product.

\subsection{Product Lines for Networking}

In this section, we show how the current solution developed in the domain of PLs can fit the variability coming from the networking (on the right side of the Fig. 2). In this scenario, the most important point is the ability to take into account all local constraints coming from manufacturing facilities. In other words, the PLs outputs must not add constraints that can limit the flexibility of each manufacturing facility in optimising the organisation of its processes and resources.

All work on PLs cited above refer to a single manufacturing facility. Therefore here we can highlight a lack of a method able to take into account this kind of variability.

\section{A Systemic Perspective for Variability Rationalisation}

In this section we use a systemic perspective in order to highlight the lacks of current approaches for the illustrated scenario. Here the aim is to describe how we can improve the PL definition to meet the variability rationalisation. Finally we show the impact of this strategy on the sustainability perspective of the enterprise.

The General Systems Theory, described for the first time in [24], is an interdisciplinary study with the system as the core concept. Starting from this work, Le Moigne built a modelling theory in [25]. He stated that a system is a structured object that functions and evolves, in an environment, for a fixed purpose.

The engineering theory based on this concept is called System Engineering (SE) [26]. For [26], three main models define the system:

1. The System requirements model contains the required system features in order to fulfil customer needs; this model is independent from solution alternatives and from technology;

2. The Logical architecture model describes how the system functions, i.e. its behaviour for the requirements fulfilment; this model is independent from technology

3. The Physical architecture model describes the set of elements that perform functions; this model is related to technologies.

\subsection{The Approach for Customisation Variability}

We propose to classify the research work on PLs according the three main models of SE:

- Product component features (i.e. physical architecture) as input: at this stage the customer (not supposed to be an expert) is not able to understand the interaction between components and evidently he is not able to understand their impacts on his needs; 
- $\quad$ Product functions (i.e. logical architecture) as input: the customer is not able to understand how functions can satisfy its needs and especially about how functions interact for doing so;

- Product specification (i.e. requirements) as input: to the customer is provided the knowledge about the effects of how the product functions (and so product components) interact for performing the product behaviour, of which specifications are the description; in this case, the customer still is not able to to evaluate the impact of the product specification on his needs.

Doing so, we can highlight a gap (Fig. 3) between the customer needs and the input of current PLs. In order to fill this gap in the configuration system: 1) customizers use market research [27], therefore the manufacturer designs the products and after looks for potential customers; 2) customizers optimize customer satisfaction [10], but that implies ability for representing and assessing the feeling of satisfaction of each customer; 3) sellers are in charge to fill this gap, performing a real requirement analysis process [28]; 4) finally, in the worst (but very usual) case, customers have to fill this gap.

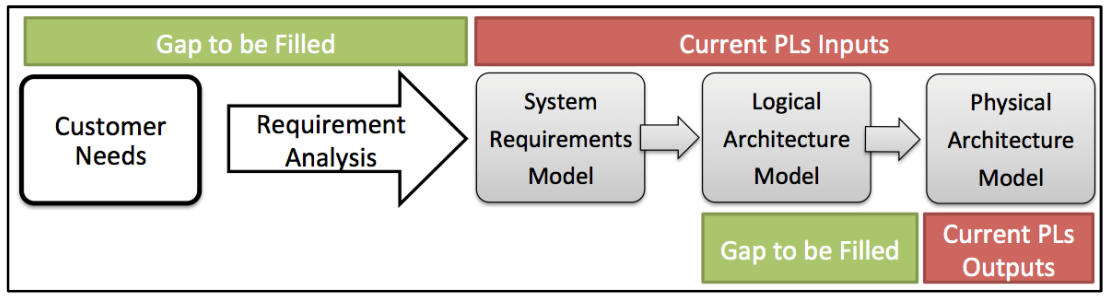

Fig. 3. Gap between current PL approaches and a PL able to cope with MC in a network.

In one-of-a-kind systems, the transformation of needs in system requirements is performed during the requirement analysis process. A definition of this process can be found in [29]: here the authors analyse the requirement analysis process in SE. This process is iterative and recursive [29]. But in MC, once the PLs is designed, the requirement analysis process has to be linear, i.e. in order to avoid a requirement analysis at each sold product, we need to formalise the link between needs and system requirements only once, at the PL design stage.

Usually, needs represent the customer point of view on the system requirements. Therefore, the requirement analysis process aims to refine needs in order to translate them into an expert view. In our vision a possible solution is to put the PL inputs at the origin of needs, i.e. the environment. In this way a PL can include the direct transformation of the customer environment into system requirements.

\subsection{The Approach for Networking Variability}

As pointed out in section 3.2, current PLs take into account only one manufacturing facilities. This means that, the output of the PL is very detailed at the technological level (Fig. 3). Applying this solution in a network of enterprises, we can have two resulting scenarios: 
1. to take into account all technological constraints coming from all manufacturing facilities; therefore, in order to optimise the efficiency of each single manufacturing facility, it is needed to take into account all constraints coming from all other network participants;

2. to develop a PL for each facility in the network; this implies an increase of the product design effort proportional to the number of enterprises in the network.

In our vision, in order to rationalise the efforts and the resources consumption, a PLs output has to be independent from any technological definition. Using the SE vision, the PLs output has to include concepts belonging to the logical architecture of the system (Fig. 3).

\subsection{From Variability Rationalisation to Sustainability}

In this section we briefly show how an appropriate design of PLs can impact the sustainability assessment of an enterprise network. Our vision of the solution, shown in the two previous sections, allows the rationalisation of the variability: i.e. we find the right compromise between resource consumption (environmental and economical pillar of sustainability) and the amount of targeted customer needs (social pillar of sustainability).

As seen in section 4.1, the link between the customer needs to the system requirements can be formalised. The implications of this formalisation are doubles:

- On the customer side, the customer is able to ask for products that he really needs;

- Therefore, on the customizer side, the enterprise develops only product that customer needs, avoiding useless resource consumption.

As seen in section 4.2, setting the PL outputs on the logical system architecture, each manufacturing facilities can optimise the resource consumption without taking into account constraints coming from other facility in the network. In this way, the facility resource consumption efficiency is not impacted by the networking strategy. Moreover, already in [30] authors showed how a function-based (i.e. logic) design can be integrated with the enterprise information systems in order to support sustainability.

\section{Conclusions and Future Works}

In this position paper, we proposed a systemic point of view for analysing the current state of the art of the variability management, particularly of the Product Lines. We also proposed our perspective to meet the variability rationalisation and we showed how the variability rationalisation can lead to sustainability in a customizer network.

We are currently analysing the scenario and working on a solution to be experimented in the Trane Company. Trane, designs, manufactures and develops air-handling systems. The typical Trane product proposes several possible customisations. This leads easily to a large variability: several thousand of combinations to cope with. Moreover, the high volume and the product complexity stress on the need of temporary partnership, usually defined on the basis of one product. 
Our future efforts will focus on a detailed design solution for a Product Lines in this scenario. In particular, we envisage to deal with this point using basics of the cybernetic [31] and systemic approaches.

\section{References}

1. Davis, S.M.: Future perfect. Addison-Wesley (1987)

2. Tseng, M.M., Jiao, J.: Mass customization. In: Handbook of Industrial Engineering, 3rd edn., pp. 684-709. Wiley, New York (2001)

3. Blecker, T., Abdelkafi, N., Kaluza, B., Kreutler, G.: Mass Customization vs. Complexity: A Gordian Knot? Presented at the 2nd International Conference An Enterprise Odyssey: Building Competitive Advantage (2004)

4. Camarinha-Matos, L., Afsarmanesh, H.: Collaborative Networks. Springer (2008)

5. Tiihonen, J., Soininen, T., Männistö, T., Sulonen, R.: State of the practice in product configuration-a survey of 10 cases in the finnish industry. In: Knowledge Intensive CAD, pp. 95-115. Chapman \& Hall (1996)

6. Forza, C., Salvador, F.: Managing for variety in the order acquisition and fulfilment process: The contribution of product configuration systems. International Journal of Production Economics 76, 87-98 (2002)

7. Forza, C., Salvador, F.: Product configuration and inter-firm co-ordination: an innovative solution from a small manufacturing enterprise. Computers in Industry 1, 37-46 (2002)

8. Zhang, J., Wang, Q., Zhong, Y., Wan, L.: Configuration-oriented product modelling and knowledge management for made-to-order manufacturing enterprises. The International Journal of Advanced Manufacturing Technology 25, 41-52 (2005)

9. Hvam, L., Haug, A., Mortensen, N.H.: Assessment of Benefits from Product Configuration Systems. In: The Proceedings of Workshop on Configuration at the 19th European Conference on Artificial Intelligence ECAI 2010, Lisbon, pp. 9-14 (2010)

10. Hong, G., Hu, L., Xue, D., Tu, Y.L., Xiong, Y.L.: Identification of the optimal product configuration and parameters based on individual customer requirements on performance and costs in one-of-a-kind production. International Journal of Production Research 46, 3297-3326 (2008)

11. Aldanondo, M., Vareilles, E.: Configuration for mass customization: how to extend product configuration towards requirements and process configuration. Journal of Intelligent Manufacturing 19, 521-535 (2008)

12. Mazo, R., Salinesi, C., Diaz, D., Djebbi, O., Lora-Michiels, A.: Constraints: The heart of domain and application engineering in the product lines engineering strategy. International Journal of Information System Modeling and Design (IJISMD) 3, 33-68 (2012)

13. Pohl, K., Bockle, G., Van Der Linden, F.: Software product line engineering. Springer (2005)

14. Lin, J., Fox, M.S., Bilgic, T.: A requirement ontology for engineering design. Concurrent Engineering 4, 279-291 (1996)

15. Inakoshi, H., Okamoto, S., Ohta, Y., Yugami, N.: Effective decision support for product configuration by using cbr. In: Proceedings of the Fourth International Conference on Case-Based Reasoning (ICCBR), Workshop Casebased Reasoning in Electronic Commerce, Vancouver, Canada (2001)

16. Janitza, D., Lacher, M., Maurer, M., Pulm, U., Rudolf, H.: A Product Model for Mass Customisation Products. In: Palade, V., Howlett, R.J., Jain, L. (eds.) KES 2003. LNCS, vol. 2774, pp. 1023-1029. Springer, Heidelberg (2003) 
17. Xie, H., Henderson, P., Kernahan, M.: Modelling and solving engineering product configuration problems by constraint satisfaction. International Journal of Production Research 43, 4455-4469 (2005)

18. Li, B., Chen, L., Huang, Z., Zhong, Y.: Product configuration optimization using a multiobjective genetic algorithm. The International Journal of Advanced Manufacturing Technology 30, 20-29 (2006)

19. Zhou, C., Lin, Z., Liu, C.: Customer-driven product configuration optimization for assemble-to-order manufacturing enterprises. The International Journal of Advanced Manufacturing Technology 38, 185-194 (2008)

20. Zhu, B., Wang, Z., Yang, H., Mo, R., Zhao, Y.: Applying fuzzy multiple attributes decision making for product configuration. Journal of Intelligent Manufacturing 19, 591598 (2008)

21. Qin, Y.H., Wei, G.X.: Product configuration based on modular product family modelling. Journal of Computational Information Systems 6, 2321-2331 (2010)

22. Wang, Y., Han, G., Ge, J., Qi, J., Xu, J.: Research on design method of demand-driven product configuration for mass customization. Journal of Advanced Manufacturing Systems 10, 117-125 (2011)

23. Djebbi, O.: L'ingénierie des exigences par et pour les lignes de produits, PhD Thesis Université Paris 1 Panthéon - Sorbonne (2010), http://hal.archivesouvertes.fr/hal-00706377/ (in French)

24. Von Bertalanffy, L.: General systems theory (1956)

25. Le Moigne, J.-L.: La théorie du système général: théorie de la modélisation. Presses Universitaires de France-PUF (1994)

26. Pyster, A., Olwell, D., Squires, A., Hutchison, N., Enck, S., Anthony, J.: A Guide to the Systems Engineering Body of Knowledge (SEBoK). Version 1.0. Stevens Institute of Technology (2012)

27. Helo, P.T., Xu, Q.L., Kyllönen, S.J., Jiao, R.J.: Integrated Vehicle Configuration SystemConnecting the domains of mass customization. Computers in Industry 61, 44-52 (2010)

28. Haskins, C., Forsberg, K.: Engineering, I.C. on S.: Systems Engineering Handbook: A Guide for System Life Cycle Processes and Activities; INCOSE-TP-2003-002-03.2. 1 (2011)

29. Bouffaron, F., Gouyon, D., Dobre, D., Morel, G.: Revisiting the interoperation relationships between Systems Engineering collaborative processes. In: 14th IFAC Symposium on Information Control Problems in Manufacturing, INCOM 2012. Elsevier, IFAC Papersonline (2012)

30. Giovannini, A., Aubry, A., Panetto, H., Dassisti, M., El Haouzi, H.: Ontology-Based System for supporting Manufacturing Sustainability. Annual Reviews in Control 36, 309317 (2012)

31. Wiener, N.: Cybernetics: or the Control and Communication in the Animal and the Machine, 2nd edn. The MIT Press (1965) 